Original Article

\title{
Mutational analysis of mitochondrial DNA in Brugada syndrome
}

\author{
Laura Stocchi $^{\text {a, } 1}$, Emanuela Polidori ${ }^{\text {b, }}{ }_{\text {, Lucia Potenza }}^{\text {b, } *, 1}$, Marco Bruno Luigi Rocchi ${ }^{\mathrm{b}}$, Cinzia Calcabrini ${ }^{\mathrm{b}}$, \\ Paolo Busacca ${ }^{c}$, Maria Capalbo ${ }^{\mathrm{d}}$, Domenico Potenza ${ }^{\mathrm{e}}$, Francesca Amati ${ }^{\mathrm{a}}$, Ruggiero Mango ${ }^{\mathrm{f}}$, \\ Francesco Romeo ${ }^{\mathrm{f}, \mathrm{g}}$, Giuseppe Novelli ${ }^{\mathrm{a}, \mathrm{h}, \mathrm{i}}$, Vilberto Stocchi ${ }^{\mathrm{b}}$ \\ a Department of Biomedicine and Prevention, University of Tor Vergata, Rome, Italy \\ ${ }^{\mathrm{b}}$ Department of Biomolecular Sciences, University of Urbino Carlo Bo, Italy \\ c Complex Operative Unit of Cardiology (UOC),Santa Maria della Misericordia Hospital, Urbino, Italy \\ d ASUR Marche-Area Vasta 1, Italy \\ e Complex Operative Unit of Cardiology (UOC), IRCCS “Casa Sollievo della Sofferenza”, San Giovanni Rotondo, Italy \\ ${ }^{f}$ Complex Operative Unit of Cardiology (UOC), Polyclinic Tor Vergata, Rome, Italy \\ ${ }^{g}$ Department of System Medicine, University of Tor Vergata, Rome, Italy \\ h St. Peter Fatebenefratelli Hospital, Rome, Italy \\ i Department of Internal Medicine, University of Arkansas for Medical Sciences and Central Arkansas Veterans Healthcare System, Little Rock, AR, USA
}

\section{A R T I C L E I N F O}

Article history:

Received 24 June 2015

Received in revised form 5 October 2015

Accepted 6 October 2015

\section{Keywords:}

Brugada syndrome

mtDNA

mtSNPs

Sequence analysis

Risk stratification

\begin{abstract}
A B S T R A C T
Background: Brugada syndrome (BrS) is a primary electrical disease associated with an increased risk of sudden cardiac death due to ventricular fibrillation. This pathology has nuclear heterogeneous genetic origins, and at present, molecular diagnostic tests on nuclear DNA cover only 30\% of BrS patients. The aim of this study was to assess the possible involvement of mitochondrial (mt) DNA variants in BrS since their etiological role in several cardiomyopathies has already been described.

Methods and Results: The whole mt genome of BrS patients was sequenced and analyzed. A specific mtDNA mutation responsible for $\mathrm{BrS}$ can be excluded, but BrS patient d-loop was found to be more polymorphic than that of control cases $(P=0.003)$. Moreover, there appears to be an association between patients with the highest number of variants $(n>20)$ and four mt Single Nucleotide Polymorphism (SNPs) (T4216C, A11251G, C15452A, T16126C) and the most severe BrS phenotype $(P=0.002)$.

Conclusions: The high substitution rate found in BrS patient mtDNA is unlikely to be the primary cause of the disease, but it could represent an important cofactor in the manifestation of the BrS phenotype.

Evidence suggesting that a specific mtDNA allelic combination and a high number of mtDNA SNPs may be associated with more severe cases of BrS represents the starting point for further cohort studies aiming to test whether this mt genetic condition could be a genetic modulator of the BrS clinical phenotype.
\end{abstract}

(C) 2015 Elsevier Inc. All rights reserved.

\section{Introduction}

Brugada syndrome (BrS) is a cardiac disorder characterized by typical electrocardiogram (ECG) alterations and a high risk of sudden death in subjects with structurally normal hearts. BrS was described for the first time in 1992 by Pedro and Josep Brugada and reportedly accounts for $20 \%$ of sudden deaths in the absence of structural heart disease and for $4 \%$ of all sudden deaths [1]. Symptoms frequently manifest themselves at night or during daytime rest periods and in combination with fever. More than $80 \%$ of Brugada patients are males, and the typical

Funding: This work was supported by a grant from the Regione Marche ASUR Marche-Area Vasta 1 Research Project: "La medicina di genere nelle malattie aritmogene ereditarie: studio delle alterazioni del DNA nucleare e mitocondriale."

* Corresponding author at: Department of Biomolecular Sciences, University of Urbino Carlo Bo, Italy. Tel.: + 39-0722-305232; fax: + 39-0722-305324.

E-mail address: lucia.potenza@uniurb.it (L. Potenza).

1 These authors equally contributed to this work age of onset is 40-45 years. Diagnosis is made on the basis of an ECG pattern showing characteristic cove-shaped ST elevation in leads V1 to V3 [2], but it is difficult to make a definitive diagnosis because ECG changes are dynamic and variable. Currently, the implantable cardioverter-defibrillator (ICD) is the only proven, effective strategy for the prevention of sudden cardiac death in patients with symptoms or a family history of sudden cardiac death, but it has several disadvantages for the patient. Diagnostic criteria used to make a decision regarding the implant of a defibrillator are based on the risk stratification proposed by Priori et al. [3] and current guidelines [4].

$\mathrm{BrS}$ is defined as a genetically transmitted disease with an autosomal dominant transmission and incomplete penetrance. Genetic mutations in the SCN5A gene, encoding the $\alpha$-subunit of the $\mathrm{Na}+$ channel, are found in $25-30 \%$ of BrS patients. Over 300 different mutations of SCN5A have been identified in association with BrS [5], and these mutations cause a loss of function of the cardiac sodium channel. Nevertheless, a negative SCN5A gene test does not rule out BrS since this 
disorder has a heterogeneous genetic basis. In fact, to date, mutations in 17 other genes [6], each responsible for a very low percentage of Brugada cases, have been described. At present, the emerging view of arrhythmia genomics suggests that BrS is a complex disorder in which the cosegregation of different mutations or genetic variants can contribute to the clinical phenotype [7-9].

It is difficult to pin down the exact incidence of $\mathrm{BrS}$ in the general population, although it is estimated to affect from 5 to 20 in every 10,000 people worldwide. Moreover, it is considered endemic in Southeast Asian countries, where the prevalence is higher [10]. As molecular diagnostic tests cover only $30 \%$ of BrS patients, it is crucial to find other genetic markers associated with the syndrome. It has been reported that several pathogenic mtDNA mutations could be the cause of cardiomyopathies and heart failure [11-15] and these mutations have also been associated with sudden death [16-19]. To the best of our knowledge, data in literature regarding the association between mtDNA and inherited arrhythmogenic diseases are not exhaustive [18,20,21], and genetic studies on the mitochondrial DNA of BrS patients have yet to be reported. Hence, this work aims to sequence and analyze the mtDNA of BrS patients to determine whether alterations in this DNA are involved in BrS.

\section{Materials and methods}

\subsection{Study samples}

This study was approved by the Human Ethics Committee of the University of Urbino Carlo Bo and was conducted according to the ethical guidelines and principles of the international Declaration of Helsinki. All participants provided their written informed consent to take part in the study. In all, 40 Caucasian BrS patients (35 males and 5 females, of which 38 were sporadic cases and 2 related cases in 1 family, $13 \mathrm{BrS}$ and $20 \mathrm{BrS}$, considering the mtDNA matrilinear heredity model) and 50 Caucasian controls (26 males and 24 females) were recruited. BrS patients subjected to the whole mtDNA sequencing and analysis were enrolled by the Comprehensive Cardiology Care Unit (UOC), "Santa Maria della Misericordia” Hospital, Urbino (Italy) and the Institute for Treatment and Research (I.R.C.C.S.), "Casa Sollievo della Sofferenza" Hospital, San Giovanni Rotondo (Italy). BrS patients enrolled to increase the study sample and control subjects were provided by the Medical Genetics Section of Tor Vergata University and by the UOC, Tor Vergata Polyclinic, Rome (Italy). BrS was diagnosed on the basis of a Type 1, Type 2, or Type 3 ECG pattern, according to current guidelines [4]. The available information on the enrolled patients is reported in Tables 1 and 2.

\subsection{Sample collection}

For each patient, peripheral blood in ethylenediaminetetraacetic acid (EDTA) tubes and buccal cells in $5 \mathrm{ml}$ of physiological solution were collected. Patients were instructed not to smoke, eat, or brush their teeth for $2 \mathrm{~h}$ before sample collection. Only peripheral blood was collected for control subjects. Total DNA from biological samples was extracted immediately or after storage at $-20^{\circ} \mathrm{C}$.

\subsection{DNA extraction and yield determination}

Total DNA from mouthwash and peripheral blood was isolated using the QIAamp DNA blood MiniKit (Qiagen, Hilden, Germany) and the automated extractor EZ1 Advanced XL (Qiagen, Hilden, Germany), respectively, according to the manufacturer's instructions. Total DNA concentration was determined by standard UV absorbance at $260 \mathrm{~nm}$ using a Nanodrop spectrophotometer (ND-1000 Spectrophotometer, ThermoScientific,Wilmington, DE 19810, USA).

\section{4. mtDNA amplification}

Twenty-three primer pairs (Table S1) were set up to amplify the entire mtDNA circular molecule. Polymerase Chain Reaction (PCR) amplifications of the whole mitochondrial DNA were carried out by

Table 1

BrS patients enrolled in the first part of the study who underwent sequencing and analysis of the whole mtDNA

\begin{tabular}{|c|c|c|c|c|c|c|}
\hline Patient ID & Basal ECG & Pharmacological test & Symptoms & $\begin{array}{c}\text { ICD } \\
\text { implantation } \\
\end{array}$ & $\begin{array}{l}\text { Nuclear genetic } \\
\text { information }\end{array}$ & $\begin{array}{c}\text { mtDNA SNP combination } \\
\text { (T4216C, A11251G, C15452A T16126C) }\end{array}$ \\
\hline 03BrS & Spontaneous type 1 & 1 & Asymptomatic & NO & SCN5A - & NO \\
\hline 04BrS & Type 2 & Flecainide type 1 & Asymptomatic & NO & n.a. & NO \\
\hline 05BrS & Type 2 & Flecainide type 1 & Asymptomatic & NO & n.a. & NO \\
\hline 06BrS & Type 3 & Flecainide type 1 & Asymptomatic & NO & n.a. & NO \\
\hline 07BrS & Type 3 & Ajmaline type 1 & Asymptomatic & NO & n.a. & NO \\
\hline 08BrS & Spontaneous type 1 & 1 & Palpitation, PAF & YES & n.a. & YES \\
\hline 09BrS & Type 3 & Ajmaline type 1 & Asymptomatic & NO & n.a. & NO \\
\hline $10 \mathrm{BrS}$ & Spontaneous type 1 & 1 & $\mathrm{CA}$ & YES & n.a. & YES \\
\hline $11 \mathrm{BrS}$ & Type 2 & Ajmaline type 1 & Asymptomatic & NO & n.a. & NO \\
\hline $13 \mathrm{BrS}$ & Spontaneous type 1 & 1 & Repeated CA & YES & SCN5A+ & YES \\
\hline $14 \mathrm{BrS}$ & Spontaneous type 1 & 1 & $\mathrm{CA}$ & YES & n.a. & YES \\
\hline $19 \mathrm{BrS}$ & Spontaneous type 1 & 1 & Asymptomatic & YES & n.a. & NO \\
\hline $20 \mathrm{BrS}$ & Spontaneous type 1 & 1 & Asymptomatic & YES & SCN5A+ & YES \\
\hline $24 \mathrm{BrS}$ & Spontaneous type 1 & 1 & Asymptomatic & YES & n.a. & YES \\
\hline $25 \mathrm{BrS}$ & Type 2 & Flecainide type 1 & Asymptomatic & YES & SCN5A+ & YES \\
\hline $26 \mathrm{BrS}$ & Spontaneous type 1 & 1 & Repeated CA & YES & n.a. & YES \\
\hline
\end{tabular}

+ positive; - negative; /: not performed; n.a.: not available. 
Table 2

BrS patients enrolled in the second part of the study and typed for the presence/absence of the mtDNA SNP combination (T4216C, A11251G, C15452A T16126C)

\begin{tabular}{|c|c|c|c|c|c|}
\hline Patient ID & Basal ECG & $\begin{array}{c}\text { ECG after } \\
\text { pharmacological test }\end{array}$ & $\begin{array}{c}\text { ICD } \\
\text { implantation }\end{array}$ & $\begin{array}{c}\text { Genetic } \\
\text { information }\end{array}$ & $\begin{array}{c}\text { SNP combination (T4216C, } \\
\text { A11251G, C15452A, T16126C) }\end{array}$ \\
\hline $36 \mathrm{BrS}$ & $\begin{array}{l}\text { Spontaneous } \\
\text { type } 1\end{array}$ & 1 & YES & SCN5A - & YES \\
\hline $42 \mathrm{BrS}$ & $\begin{array}{l}\text { Spontaneous } \\
\text { type } 1\end{array}$ & 1 & NO & SCN5A - & YES \\
\hline $45 \mathrm{BrS}$ & $\begin{array}{l}\text { Spontaneous } \\
\text { type } 1\end{array}$ & 1 & YES & SCN5A- & NO \\
\hline $46 \mathrm{BrS}$ & $\begin{array}{l}\text { Spontaneou } \\
\text { type } 1\end{array}$ & 1 & YES & n.a. & YES \\
\hline $50 \mathrm{BrS}$ & $\begin{array}{l}\text { Spontaneous } \\
\text { type } 1\end{array}$ & 1 & YES & SCN5A - & NO \\
\hline $21 \mathrm{BrS}$ & Type 2 & Ajmalina type 1 & YES & $\begin{array}{l}\text { HERG + } \\
\text { SCN5A - }\end{array}$ & NO \\
\hline $22 \mathrm{BrS}$ & Type 2 & Ajmalina type 1 & NO & SCN5A- & YES \\
\hline $23 \mathrm{BrS}$ & Type 2 & Ajmalina type 1 & NO & n.a. & YES \\
\hline $31 \mathrm{BrS}$ & Type 2 & Flecainide type 1 & NO & SCN5A - & NO \\
\hline $32 \mathrm{BrS}$ & Type 2 & Flecainide type 1 & YES & SCN5A- & NO \\
\hline $33 \mathrm{BrS}$ & Type 2 & Flecainide type 1 & NO & SCN5A - & NO \\
\hline $34 \mathrm{BrS}$ & Type 2 & Flecainide type 1 & NO & SCN5A - & NO \\
\hline $35 \mathrm{BrS}$ & Type 2 & Flecainide type 1 & YES & SCN5A - & NO \\
\hline $37 \mathrm{BrS}$ & Type 2 & Flecainide type 1 & NO & SCN5A - & NO \\
\hline $38 \mathrm{BrS}$ & Type 2 & Flecainide type 1 & YES & n.a. & NO \\
\hline 39BrS & Type 2 & Flecainide type 1 & YES & n.a. & NO \\
\hline $40 \mathrm{BrS}$ & Type 2 & Flecainide type 1 & NO & n.a. & YES \\
\hline $41 \mathrm{BrS}$ & Type 2 & Flecainide type 1 & YES & SCN5A - & NO \\
\hline $43 \mathrm{BrS}$ & Type 2 & Flecainide type 1 & NO & SCN5A - & NO \\
\hline $44 \mathrm{BrS}$ & Type 2 & Flecainide type 1 & YES & SCN5A - & NO \\
\hline $47 \mathrm{BrS}$ & Type 2 & Flecainide type 1 & YES & SCN5A - & NO \\
\hline $48 \mathrm{BrS}$ & Type 2 & Flecainide type 1 & YES & SCN5A+ & NO \\
\hline $49 \mathrm{BrS}$ & Type 2 & Flecainide type 1 & NO & n.a. & NO \\
\hline $51 \mathrm{BrS}$ & Type 2 & Flecainide type 1 & YES & n.a. & NO \\
\hline
\end{tabular}

/: not performed; + positive; - negative; n.a.: not available.

amplifying 23 overlapping segments. Each primer pair was checked on the NCBI Website to ascertain its specificity. In addition, specificity for mtDNA target sequences of designed primers was tested on DNA from osteosarcoma 143B.TK2 Rho0 cells completely lacking mtDNA, kindly provided by Prof. D. Bellizzi from Calabria University (Italy) (Fig. S1).

The PCR reactions were performed in a total volume of $25 \mu \mathrm{l}$ containing $50 \mathrm{ng}$ of total DNA, $2.5 \mu \mathrm{l}$ of Buffer $10 \times, 2 \mu \mathrm{l}$ of $\mathrm{MgCl} 225 \mathrm{mM}, 5 \mu \mathrm{l}$ of dNTPs $1.25 \mathrm{mM}, 10 \mathrm{nmol}$ of each primer pair and $0.125 \mu \mathrm{l}$ of Ampli Taq Gold 5U/ $\mu \mathrm{l}$ (Applied Biosystems, Foster City, CA, USA). The reaction mixture was incubated for $10 \mathrm{~min}$ at $94^{\circ} \mathrm{C}$ and then subjected to 30 cycles of $1 \mathrm{~min}$ at $94^{\circ} \mathrm{C}, 1 \mathrm{~min}$ at $59-62^{\circ} \mathrm{C}$ (according to the Tm of each primer pair), and $1 \mathrm{~min}$ at $72^{\circ} \mathrm{C}$. All PCR product sizes fell within the 800-1000-bp range; the specificity of each amplicon was assessed by migration on agarose gel at $2.5 \%$.

\section{5. mtDNA sequencing and analysis}

The whole mtDNA of $16 \mathrm{BrS}$ patients (Table 1 ) was processed amplifying 23 overlapping segments and sequenced by the Sanger Method in sense and antisense directions using the Big Dye Terminator Reaction on an ABI 3130xL automated sequencer (Applied Biosystems, Foster City, CA, USA). Each mtDNA sequence was compared with the revised 
Table 3

Predicted haplogroup of BrS patients obtained using the Mitomaster program (www.mitomap.org)

\begin{tabular}{|c|c|c|c|}
\hline Patient ID & $\begin{array}{c}\text { Age at } \\
\text { sampling }\end{array}$ & Sex & $\begin{array}{c}\text { Predicted } \\
\text { haplogroup }\end{array}$ \\
\hline 03BrS & 22 & M & $\mathrm{H} 2$ \\
\hline 04BrS & 48 & $\mathrm{~F}$ & H8a \\
\hline 05BrS & 47 & M & $\mathrm{X} 2 \mathrm{~m}$ \\
\hline 06BrS & 30 & $\mathrm{M}$ & $\mathrm{H} 8 \mathrm{c}$ \\
\hline 07BrS & 42 & M & N1b \\
\hline 08BrS & 72 & M & $\mathrm{J} 1 \mathrm{c}^{*}$ \\
\hline 09BrS & 51 & M & $\mathrm{H} 8$ \\
\hline $10 \mathrm{BrS}$ & 76 & M & $J 1 c^{*}$ \\
\hline $11 \mathrm{BrS}$ & 59 & M & V \\
\hline $13 \mathrm{BrS}$ & 36 & M & $\mathrm{T} 2 \mathrm{c}^{*}$ \\
\hline $14 \mathrm{BrS}$ & 38 & M & $\mathrm{J} 2 \mathrm{a}^{*}$ \\
\hline $19 \mathrm{BrS}$ & 34 & M & $\mathrm{H}$ \\
\hline $20 \mathrm{BrS}$ & 40 & M & $\mathrm{T} 2 \mathrm{c}^{*}$ \\
\hline $24 \mathrm{BrS}$ & 71 & M & $\mathrm{J} 1 \mathrm{c}^{*}$ \\
\hline $25 \mathrm{BrS}$ & 57 & $\mathrm{~F}$ & $\mathrm{~J} 1 \mathrm{~b}^{*}$ \\
\hline $26 \mathrm{BrS}$ & 43 & M & $\mathrm{J} 2 \mathrm{~b}^{*}$ \\
\hline
\end{tabular}

*The asterisk indicates the sub-haplogroups deriving from the JT haplogroup.

Cambridge Reference Sequence (NC_012920) [22] in the Mitomap database (www.mitomap.org) using SeqScape 2.5V, Sequencing Analysis 5.2 (Applied Biosystems, Foster City, CA, USA) and DNA Baser v 3.5 (Heracle BioSoft S.R.L.) softwares. MitoMaster was used to determine the haplogroup of each patient analyzed (Table 3 ) and to identify polymorphisms [23]. To reduce the possibility of sequencing errors, we repeated the sequencing reaction in all samples containing a nucleotide variant, and only those variants confirmed in independent sequencing reactions were considered as true variants.

The variants that have yet to be annotated in the Mitomap database were validated by also checking for their presence in buccal cell samples from the same Brugada patients and for their absence in controls. Novel variants were further analyzed for their potential pathogenicity based on their position in mtDNA (coding or non coding region) and the conservation of the predicted amino acid, if the variant occurred within a coding region (Table S2).

\subsection{Statistical analysis}

A multivariate logistic regression analysis was performed to identify risk factors associated with BrS (using a nested model to take related data into account); status (healthy subjects vs. Brugada patients) was considered as the dependent variable, and mtDNA Single Nucleotide Polymorphisms (SNPs) (T4216C A11251G, T15452C and T16126C) and the total number of d-loop variants were considered as potentially prognostic factors. The Mann-Whitney test was used to compare the dloop and coding region of BrS patients with a high number of variants (SNPs $>20$ ), as discussed in the "Results" section. As an exploratory analysis, the Fisher's Exact Test on mtDNA SNPs was performed to compare Brugada patients and to define their risk of developing the severe phenotype of the syndrome.

A familywise significance level $P<0.05$ was fixed for all analyses, using Bonferroni's correction as appropriate. The statistical analysis
Table 4

Summary of the variants found in BrS patient mtDNA and their localization in the mtDNA genome

\begin{tabular}{|c|c|c|c|c|c|c|c|c|}
\hline \multicolumn{9}{|c|}{ Number of variants in each BrS patient } \\
\hline Patient ID & d-loop & $\begin{array}{c}\text { ND } \\
\text { subunits }\end{array}$ & $\begin{array}{c}\text { COX } \\
\text { subunits }\end{array}$ & $\begin{array}{c}\text { ATP } \\
\text { subunits }\end{array}$ & $\begin{array}{c}\text { Cytb } \\
\text { subunit }\end{array}$ & rRNAs & tRNAs & $\begin{array}{l}\text { Total } n^{\circ} \text { of } \\
\text { variants }\end{array}$ \\
\hline 07BrS & 11 & 10 & 4 & 3 & 1 & 5 & - & 34 \\
\hline $13 \mathrm{BrS}$ & 10 & 9 & 3 & 2 & 4 & 3 & 2 & 33 \\
\hline $14 \mathrm{BrS}$ & 13 & 12 & 2 & - & 3 & 1 & 2 & 33 \\
\hline $20 \mathrm{BrS}$ & 10 & 9 & 3 & 2 & 4 & 3 & 2 & 33 \\
\hline $26 \mathrm{BrS}$ & 13 & 7 & 2 & - & 5 & 1 & 2 & 30 \\
\hline $25 \mathrm{BrS}$ & 12 & 9 & 2 & 1 & 2 & 3 & - & 29 \\
\hline 08BrS & 11 & 10 & 1 & 1 & 3 & 2 & - & 28 \\
\hline $10 \mathrm{BrS}$ & 7 & 9 & 2 & - & 3 & 3 & - & 24 \\
\hline $24 \mathrm{BrS}$ & 11 & 5 & 1 & - & 3 & 2 & - & 22 \\
\hline 05BrS & 9 & 4 & 2 & - & 1 & 2 & - & 18 \\
\hline 06BrS & 10 & 3 & & 1 & - & 1 & - & 15 \\
\hline $04 \mathrm{BrS}$ & 8 & 1 & 1 & - & - & 1 & - & 11 \\
\hline 09BrS & 7 & 2 & 1 & - & - & 1 & - & 11 \\
\hline $11 \mathrm{BrS}$ & 4 & 2 & 1 & - & 1 & 1 & 1 & 10 \\
\hline $19 \mathrm{BrS}$ & 3 & 3 & - & - & - & - & - & 6 \\
\hline 03BrS & 2 & 1 & - & - & - & - & - & 3 \\
\hline $\begin{array}{c}\text { Total } n^{\circ} \text { not } \\
\text { repeated } \\
\text { variants }\end{array}$ & 58 & 52 & 15 & 9 & 9 & 9 & 6 & 158 \\
\hline
\end{tabular}

was performed using the Statistical Package for Social Science (SPSS) program for Windows, Version 13.0; SPSS, Chicago, IL, USA.

\section{Results}

In order to investigate a possible association between mtDNA alteration/s and BrS, we analyzed the mtDNA of $16 \mathrm{BrS}$ patients (Table 1). We annotated a total of 343 mtDNA variants (Table S2), 158 of which were not repeated. All the mtDNA substitutions were checked in the Mitomap database, and we found 85 variants in the peptide-coding region, 9 in rRNA genes, 6 in tRNA genes, and 58 in the d-loop (Tables 4 and S2).

One novel nucleotide synonymous variant in the COX3 gene (C9600T) was identified in both the peripheral blood and buccal cell samples of one patient, while it was absent in controls $(n=50)$. On the contrary, one nonsynonymous variant (the transition T8864C) in peptide-coding region in ATPase- 6 was found in another patient and confirmed in both his peripheral blood and buccal cell samples. This variant had a very low frequency in GenBank and was absent in controls.

Although we failed in our attempt to identify a common mutation in the mtDNA of BrS patients under study, our analysis allowed us to make some noteworthy observations.

First, we found that BrS subjects tended to have a higher substitution rate in the mtDNA d-loop compared to subjects in the control group ( $P=0.003$, significant after Bonferroni's correction), as revealed by the multivariate logistic regression analysis (using a nested model to take into account the two brothers in the BrS group). In particular, we investigated the frequency of $38 \mathrm{~d}$-loop variants common to $\mathrm{BrS}$ patients and the control group. As reported in Fig. 1, 35 SNPs occurred with a greater incidence in BrS patients, one SNP occurred with the same frequency, and only two variants occurred more frequently in the control group.

Secondly, we found that $56 \%$ of $\mathrm{BrS}$ patients $(07 \mathrm{BrS}, 08 \mathrm{BrS}, 10 \mathrm{BrS}$, 13BrS, 14BrS, 20BrS, 24BrS, 25BrS, 26BrS) shared four polymorphisms T4216C, A11251G, C15452A, T16126C - and interestingly, this mtDNA allelic combination was significantly associated $(P=0.002$, significant after Bonferroni's correction) with a severe clinical state in which the subjects exhibited a spontaneous Type 1 ECG and symptoms, that is, syncope, cardiac arrest (CA), or paroxysmal atrial fibrillation (PAF) events (symptomatic subjects). Furthermore, two of these SNPs (T4216C and T16126C) determine the membership of all these patients 
in the same haplogroup JT (Tables 3 and p5). This observation prompted us to evaluate the association of the four mtSNPs in 50 control group samples, and a low frequency of about 20\% was estimated. Members of the control group belonged to the general population, and we had no available information on their cardiovascular status; hence, the frequency may be lower in healthy subjects. Finally, we also observed that this group of patients is highly polymorphic (number of SNPs $>20$ ) and most of the SNPs fall in the mtDNA coding region rather than in the d-loop (Fig. 2, $P=0.003$ significant after Bonferroni's correction).

In order to further investigate the possible association between this mitochondrial allelic combination and a more severe BrS phenotype an additional $24 \mathrm{BrS}$ patients (Table 2), either spontaneous Type 1 ECG $(n=14)$ or induced Type 1 ECG $(n=26)$ was enrolled in the study, bringing the total number of BrS cases to 40 . They were typed for the presence/absence of the mtDNA SNP combination, and once again we confirmed the association between spontaneous Type 1 ECG BrS subjects and the four mtDNA SNP combinations, as revealed by Fisher's Exact Test analysis ( $P=0.001$, significant after Bonferroni's correction).

\section{Discussion}

Mutations in mitochondrial DNA have been shown to contribute to the genesis of various diseases, including neurological disorders, myopathies, and encephalomyopathies. Moreover, mtDNA point mutations have been reported in patients with cardiomyopathy, either alone or as a part of a multisystem disorder [17,24-29].

Oxidative stress has recently been implicated in the pathophysiology of cardiac arrhythmia [30,31]. In fact, the overproduction of mitochondrial reactive oxygen species observed in human embryonic kidney cells stably expressing the cardiac sodium channel SCN5A leads to a reduced INa [30] and a decrease in SCN5A mRNA transcription [32]. Mitochondrial DNA is very sensitive to oxidative stress, as supported by new missense mtDNA mutations recently detected in sudden cardiac deaths caused by cardiomyopathy [18], as well as by the accumulation of mitochondrial genome variations in patients affected by long QT syndrome (LQTS) [20,21], an inherited channelopathy responsible for sudden cardiac death in young individuals. Moreover, ion channels are adenosine triphosphate (ATP) sensitive and the heart is highly dependent on oxidative energy generated in the mitochondria, thus it cannot be excluded that arrhythmia may be due to mitochondrial dysfunction $[20,21,33,34]$.
In our research, only one novel variant (C9600T) was detected in Patient $\mathrm{BrSO4}$, and it was a synonymous variant. Hence, it is reasonable to surmise that it does not have pathological effects. On the contrary, among the nonsynonymous SNPs in the peptide-coding region, the transition T8864C in ATPase-6, which causes an amino acid change from valine to alanine, was detected in Patient BrS06 and not in controls, showing a very low frequency. This variant is located in a highly conserved domain of the ATPase- 6 subunit of Complex V. The ATPase- 6 plays a key role in the coupling of proton flow [35]; thus, it could affect the activity of ATPase-6. Indeed, there is evidence that the substitution of an amino acid with another chemically similar, as in the present case valine versus alanine both nonpolar neutral amino acids, could reduce the activity of the enzyme in question [36,37]. However, additional "in vitro" molecular and biochemical studies (RNA processing and protein expression) are necessary to elucidate the biological effects of this sequence variation before any pathogenic significance can be assigned. In literature, mutational analyses to evaluate the involvement of mtDNA in sudden cardiac death describe mtDNA mutations in the ATPase-6 gene in patients affected by dilated cardiomiopathy [18] and LQTS [21]. In addition, Khatami and Heidary [38] report having found the G9055A mutation in the ATPase- 6 gene in 4 Iranian Brugada patients. This mutation modifies the hydropathy index and the protein charge probably altering the structure of the proton channel contained in Complex V; thus, it was considered potentially pathologic.

In some cases, BrS has been proposed to be the cause of sudden infant death syndrome (SIDS) $[39,40]$. Indeed, these disorders display common features, such as aberrant sodium channel function and fatal heart arrhythmias. Evidence suggesting that in SIDS a higher substitution frequency in the mtDNA hypervariable region (I) has been found [16] prompted us to perform a careful analysis of Brugada patients' d-loop. Interestingly, this region resulted more polymorphic in BrS subjects than in control samples $(P=0.003$, significant after Bonferroni's correction). Although the substitutions in the d-loop may not be lethal in themselves, they could promote mtDNA instability [20,41], such as deleterious mutations in other mtDNA coding regions, which could lead to a mitochondrial impairment $[17,41,42]$. Furthermore, the d-loop contains regulatory elements involved in mtDNA replication; thus, mutations in this region could affect mtDNA copy number [43], and the consequent reduced adenosine triphosphate production might represent a further risk factor for BrS.

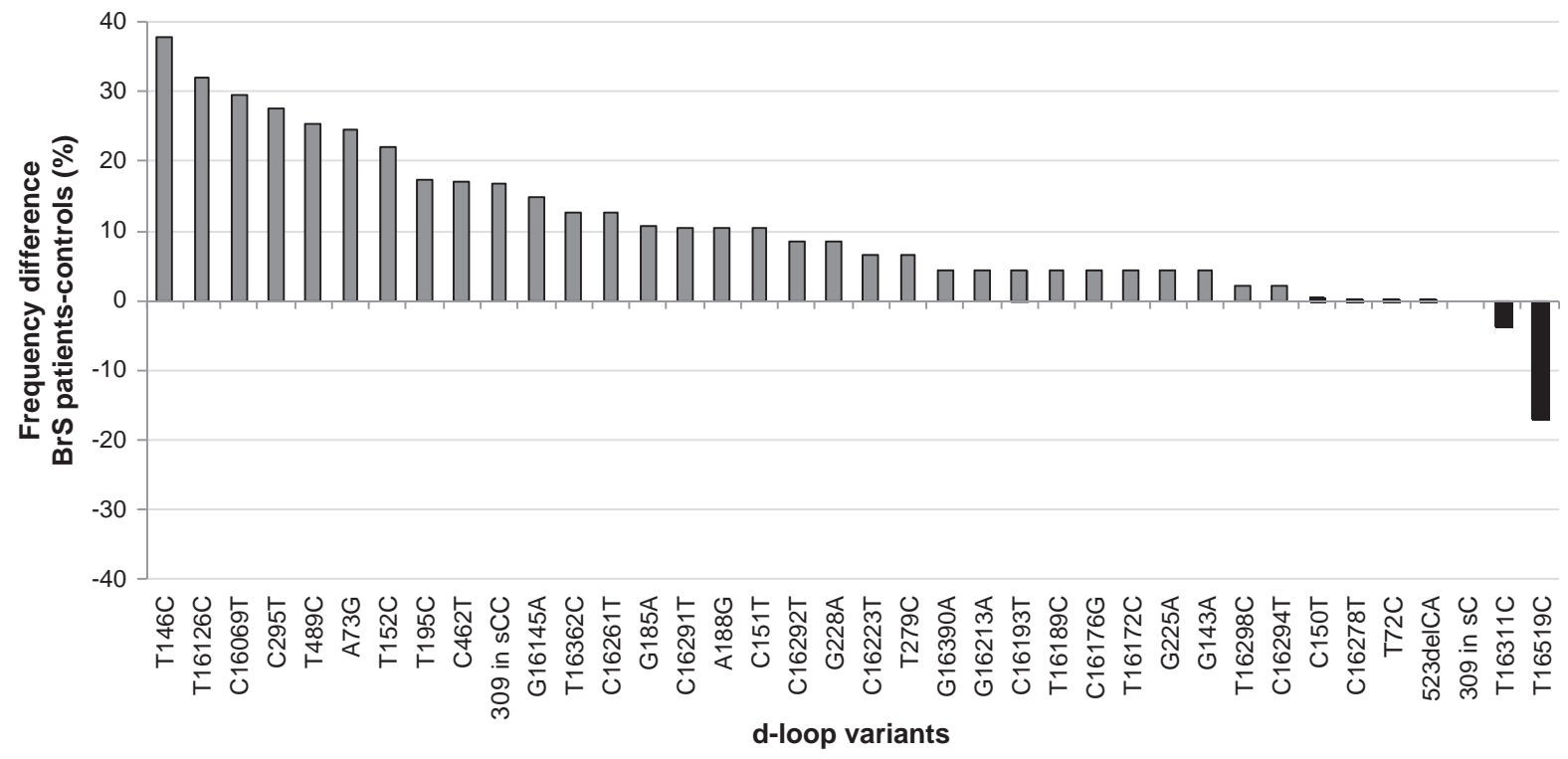

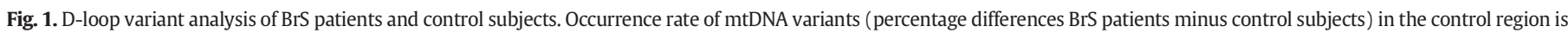
calculated for the SNPs in common between the two groups. In grey positive differences, in black negative differences. 
Table 5

Important results from the first part of the study

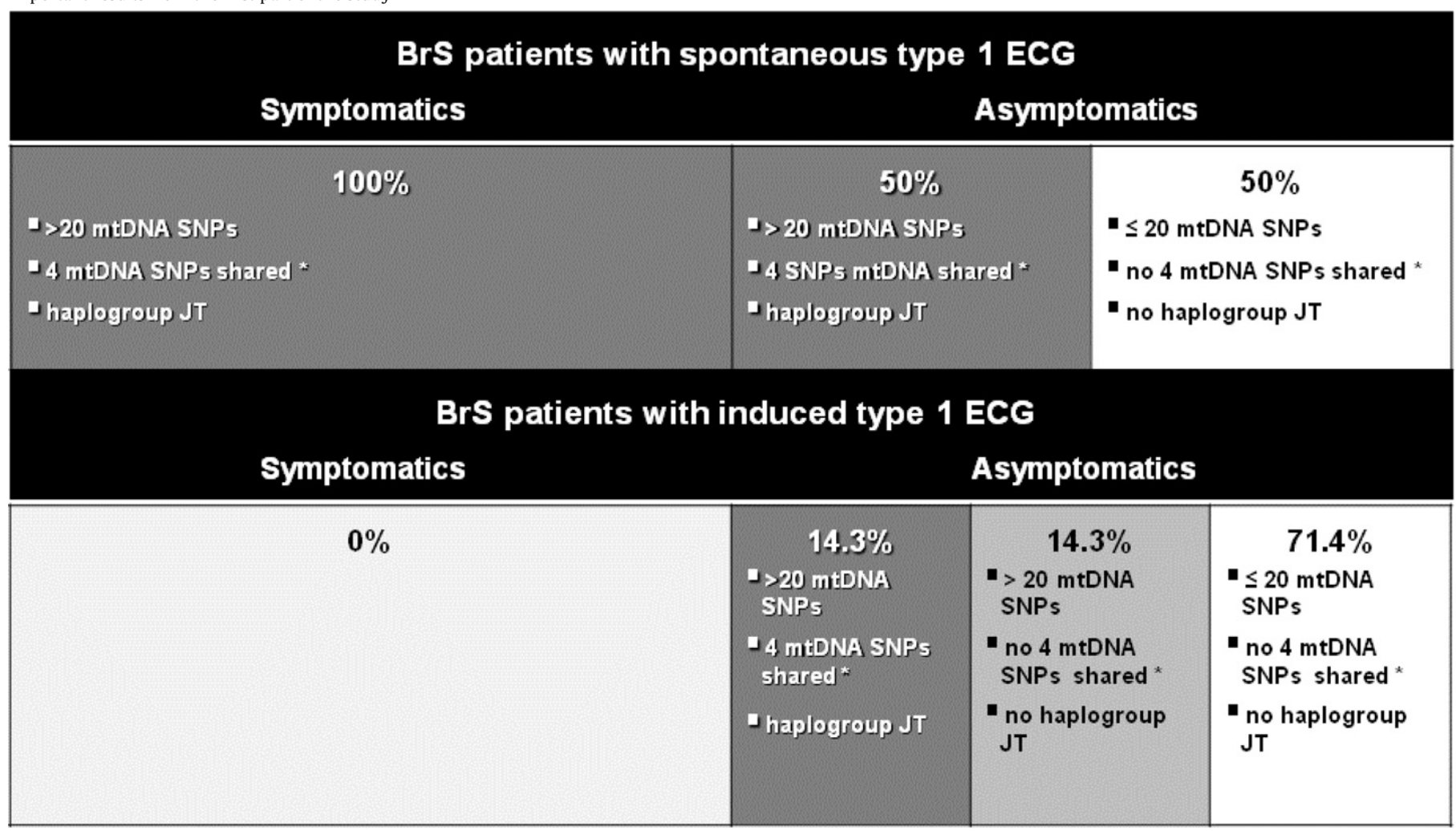

*mtDNA allelic combination T4216C, A11251G, C15452A and T16126.

We also carefully analyzed the distribution of all mtDNA SNPs detected in BrS patients along the mitochondrial genome since the combined effect of d-loop variants together with coding region SNPs can contribute to the development of various human diseases [44]. Surprisingly, we found that BrS subjects characterized by a highly polymorphic mtDNA accumulate the variants mainly in the coding region and not in the d-loop ( $P=0.003$, significant after Bonferroni's correction). Interestingly, all symptomatic patients share a combination of four SNPs: T4216C, A11251G, C15452A, and T16126. Two of these SNPs (T4216C and T16126C) characterize the JT haplogroup, derived from the $R$ superhaplogroup, a rooting ancestor for most of the Caucasian population. Since several mtDNA haplogroups have been found to be associated with certain human diseases $[45,46]$, we hypothesize a possible correlation between the clinical characteristics of BrS patients and their mitochondrial haplogroup (Tables 1 and 3).

The significant association $(P=0.002$, significant after Bonferroni's correction) found between the presence of the SNP combination T4216C, A11251G, C15452A and T16126 - and BrS patients characterized by an acute clinical state (spontaneous Type 1 ECG and symptoms such as syncope, CA or PAF events) suggests that this mitochondrial genetic condition could represent a risk factor for a more severe BrS phenotype for which ICD implantation is recommended according to current guidelines [4].

If we examine the characteristics of patient $13 \mathrm{BrS}$, we find evidence supporting our hypothesis. Indeed, he is characterized by a spontaneous Type 1 ECG, ICD implantation with repeated CAs, the mtDNA allelic combination, and a high number of mtDNA SNPs. On the contrary, Patient $19 \mathrm{BrS}$, although characterized by a spontaneous Type $1 \mathrm{ECG}$, is asymptomatic, does not show the allelic combination and has only six mtDNA SNPs. Hence, according to our hypothesis, he may be less likely to develop a severe form of the syndrome, and it is therefore fundamental that we follow up Patient 19BrS to test this supposition. Finally, we also observed that the above-mentioned Patient 13BrS and his brother,
Patient 20BrS (asymptomatic, positive for SCN5A and ICD implanted), show the same mtDNA pattern (highly polymorphic and positively typed for the four mtSNPs), inherited from their affected mother. This mtDNA condition may put Patient 20BrS at greater risk of developing a more severe form of the syndrome and thus justify his ICD implantation. Moreover, taking into consideration the maternal inheritance of the mtDNA, the mitochondrial analysis could be important for prognostic purposes. Indeed, the clinical expressivity of $\mathrm{BrS}$ in successive generations should change according to the parent who carries the mtDNA combination T4216C, A11251G, C15452A and T16126.

The results obtained from this initial observational study on $16 \mathrm{BrS}$ patients prompted us to investigate the presence of the SNP combination T4216C, A11251G, C15452A and T16126 in a wider group of BrS patients $(n=40)$, who were either spontaneous Type 1 ECG or induced. The preferential association of the mtDNA allelic combination with spontaneous Type 1 ECG subjects, who were mainly symptomatic ( $P=0.001$, significant after Bonferroni's correction), might indicate that induced Type 1 ECG BrS patients without the allelic combination should be less likely to develop a severe form of the syndrome. This is consistent with current risk stratification system, which indicates a better prognosis for induced Type 1 ECG patients than for patients with spontaneous Type 1 ECGs. Thus, taken together, our data suggest that Brugada patients characterized by a highly polymorphic mtDNA and a specific mtDNA SNP combination (T4216C, A11251G, C15452A and T16126C) could have a greater risk of developing a more severe form of the syndrome. At present, it is speculative to suggest that this mitochondrial genetic condition could be used to improve risk stratification due to the limited sample size in this investigation and the need to follow up asymptomatic patients to monitor the possible development of symptoms.

Nevertheless, considering that Lizotte et al. [47] have already proposed that common genetic variants in SCN5A gene may influence the final clinical phenotype of BrS, we suggest that mitochondrial SNPs 


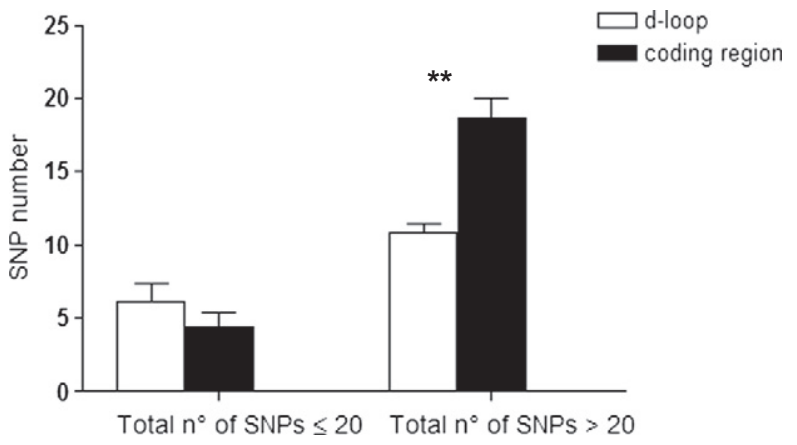

Fig. 2. mtDNA SNP distribution in BrS patients. Comparison of SNP number distributed into d-loop and coding region (mRNA, tRNA, and rRNA) performed on 16 BrS subjects. The comparisons statistically significant is d-loop versus coding region inside the group characterized by a number of SNPs $>20\left({ }^{* *}, P<0.01\right)$.

may also have a role. Hence, in the future, our data on mtDNA variants could integrate nuclear genetic evidence $[47,48]$ and thus constitute an important part of a new pilot model for risk stratification. Such a model, based not only on clinical features but also on nuclear and mitochondrial genetic markers, could be particularly helpful for asymptomatic patients.

\section{Conclusions}

This investigation constitutes the first attempt to find an association between mtDNA mutation/s and BrS. The results described herein show that a specific mtDNA variation responsible for this pathology can be excluded. Although we found a high substitution rate in the mtDNA of BrS patients, mtDNA alterations are not likely to represent the primary cause of the disease. This cause probably lies in nuclear mutation/s and/or in still unknown epigenetic modifications, but mtDNA alterations could be an important cofactor for a critical BrS phenotype, a hypothesis which is consistent with the recently advanced concept that $\mathrm{BrS}$ is not an exclusively Mendelian disease [7-9,47,48]. More specifically, the data described herein suggest that BrS patients with a specific mtDNA allelic combination (T4216C, T16126C, A11251G and C15452A) and high number of mtDNA variants are more likely to develop a severe clinical phenotype of the syndrome; thus, this mitochondrial genetic condition could represent a genetic modulator of BrS phenotype.

Supplementary data to this article can be found online at http://dx. doi.org/10.1016/j.carpath.2015.10.001.

\section{Acknowledgments}

The authors are indebted to Prof. D. Bellizzi of Calabria University (Italy) for providing DNA from human osteosarcoma 143B.TK2 Rho0 cells used to test the specificity of mtDNA primer pairs. The authors are also grateful to Timothy Clifford Bloom (the Center for Languages, University of Urbino Carlo Bo) for his critical reading of our manuscript and helpful comments.

\section{References}

[1] Brugada P, Brugada J. Right bundle branch block, persistent ST segment elevation and sudden cardiac death: a distinct clinical and electrocardiographic syndrome. A multicenter report. J Am Coll Cardiol 1992;20:1391-6.

[2] Antzelevitch C, Brugada P, Borggrefe M, Brugada J, Brugada R, Corrado D, et al. Brugada syndrome: report of the second consensus conference: endorsed by the Heart Rhythm Society and the European Heart Rhythm Association. Circulation 2005;111:659-70.

[3] Priori SG, Napolitano C, Gasparini M, Pappone C, Della Bella P, Giordano U, et al Natural history of Brugada syndrome: insights for risk stratification and management. Circulation 2002;105:1342-7.

[4] Priori SG, Wilde AA, Horie M, Cho Y, Behr ER, Berul C, et al. Executive summary: HRS/EHRA/APHRS expert consensus statement on the diagnosis and manage- ment of patients with inherited primary arrhythmia syndromes. Europace 2013:15:1389-406.

[5] Kapplinger JD, Tester DJ, Alders M, Benito B, Berthet M, Brugada J, et al. An international compendium of mutations in the SCN5A-encoded cardiac sodium channel in patients referred for Brugada syndrome genetic testing. Heart Rhythm 2010;7: 33-46.

[6] Nielsen MW, Holst AG, Olesen SP, Olesen MS. The genetic component of Brugada syndrome. Front Physiol 2013;4:179.

[7] Roden DM. Human genomics and its impact on arrhythmias. Trends Cardiovasc Med 2004;14:112-6.

[8] Probst V, Wilde AA, Barc J, Sacher F, Babuty D, Mabo P, et al. SCN5A mutations and the role of genetic background in the pathophysiology of Brugada syndrome. Circ Cardiovasc Genet 2009;2:552-7.

[9] Bezzina CR, Barc J, Mizusawa Y, Remme CA, Gourraud J-B, Simonet F, et al. Common variants at SCN5A-SCN10A and HEY2 are associated with Brugada syndrome, a rare disease with high risk of sudden cardiac death. Nat Genet 2013;45:1044-9.

[10] Brugada R, Campuzano O, Sarquella-Brugada G, Brugada J, Brugada P. Brugada syndrome. Methodist Debakey Cardiovasc J 2014;10:25-8.

[11] Goto Y, Nonaka I, Horai S. A mutation in the tRNA(Leu)(UUR) gene associated with the MELAS subgroup of mitochondrial encephalomyopathies. Nature 1990;348: 651-3.

[12] Nan DN, Fernandez-Ayala M, Infante J, Matorras P, Gonzalez-Macias J. Progressive cardiomyopathy as manifestation of mitochondrial disease. Postgrad Med J 2002; 78:298-9.

[13] Zhu H-Y, Wang S-W, Liu L, Li Y-H, Chen R, Wang L, et al. A mitochondrial mutation A4401G is involved in the pathogenesis of left ventricular hypertrophy in Chinese hypertensives. Eur J Hum Genet 2009;17:172-8.

[14] Merante F, Myint T, Tein I, Benson L, Robinson BH. An additional mitochondrial tRNA(Ile) point mutation (A-to-G at nucleotide 4295) causing hypertrophic cardiomyopathy. Hum Mutat 1996;8:216-22.

[15] Casali C, Santorelli FM, D'Amati G, Bernucci P, DeBiase L, DiMauro S. A novel mtDNA point mutation in maternally inherited cardiomyopathy. Biochem Biophys Res Commun 1995;213:588-93.

[16] Opdal SH, Rognum TO, Vege A, Stave AK, Dupuy BM, Egeland T. Increased number of substitutions in the D-loop of mitochondrial DNA in the sudden infant death syndrome. Acta Paediatr 1998;87:1039-44.

[17] Opdal SH, Vege A, Egeland T, Musse MA, Rognum TO. Possible role of mtDNA mutations in sudden infant death. Pediatr Neurol 2002;27:23-9.

[18] Kobayashi M, Nakamura S, Murakami C, Maeda K, Irie W, et al. Mutational analysis of the mitochondrial DNA detected in sudden cardiac death caused by cariomyopathy. Kitasato Med J 2011;41:127-35.

[19] Zaragoza MV, Fass J, Diegoli M, Lin D, Arbustini E. Mitochondrial DNA variant discovery and evaluation in human cardiomyopathies through next-generation sequencing. PLoS One 2010;5, e12295.

[20] Khatami M, Houshmand M, Sadeghizadeh M, Eftekharzadeh M, Heidari MM, Saber S, et al. Accumulation of mitochondrial genome variations in Persian LQTS patients: a possible risk factor? Cardiovasc Pathol 2010;19:e21-7.

[21] Khatami F, Mehdi Heidari M, Houshmand M. The mitochondrial DNA mutations associated with cardiac arrhythmia investigated in an LQTS family. Iran J Basic Med Sci 2014;17:656-61.

[22] Andrews RM, Kubacka I, Chinnery PF, Lightowlers RN, Turnbull DM, Howell N. Reanalysis and revision of the Cambridge reference sequence for human mitochondrial DNA. Nat Genet 1999;23:147.

[23] Brandon MC, Ruiz-Pesini E, Mishmar D, Procaccio V, Lott MT, Nguyen KC, et al. MITOMASTER: a bioinformatics tool for the analysis of mitochondrial DNA sequences. Hum Mutat 2009;30:1-6.

[24] Obayashi T, Hattori K, Sugiyama S, Tanaka M, Tanaka T, Itoyama S, et al. Point mutations in mitochondrial DNA in patients with hypertrophic cardiomyopathy. Am Heart J 1992;124:1263-9.

[25] Houshmand M, Montazeri M, Kuchekian N, Noohi F, Nozar G, Zamani A. Is 8860 variation a rare polymorphism or associated as a secondary effect in HCM disease? Arch Med Sci 2011;7:242-6.

[26] Li YY, Maisch B, Rose ML, Hengstenberg C. Point mutations in mitochondrial DNA of patients with dilated cardiomyopathy. J Mol Cell Cardiol 1997;29: 2699-709.

[27] Marin-Garcia J, Goldenthal MJ, Ananthakrishnan R, Pierpont ME. The complete sequence of mtDNA genes in idiopathic dilated cardiomyopathy shows novel missense and tRNA mutations. J Card Fail 2000;6:321-9.

[28] Ruppert V, Nolte D, Aschenbrenner T, Pankuweit S, Funck R, Maisch B. Novel point mutations in the mitochondrial DNA detected in patients with dilated cardiomyopathy by screening the whole mitochondrial genome. Biochem Biophys Res Commun 2004;318:535-43.

[29] Schrijver I, Pique LM, Traynis I, Scharfe C, Sehnert AJ. Mitochondrial DNA analysis by multiplex denaturing high-performance liquid chromatography and selective sequencing in pediatric patients with cardiomyopathy. Genet Med 2009;11:118-26.

[30] Liu M, Liu H, Dudley SC. Reactive oxygen species originating from mitochondria regulate the cardiac sodium channel. Circ Res 2010;107:967-74.

[31] Tanaka M, Nakamura K, Kusano KF, Morita H, Ohta-Ogo K, Miura D, et al. Elevated oxidative stress is associated with ventricular fibrillation episodes in patients with Brugada-type electrocardiogram without SCN5A mutation. Cardiovasc Pathol 2011;20:e37-42.

[32] Shang LL, Sanyal S, Pfahnl AE, Jiao Z, Allen J, Liu H, et al. NF-kappaB-dependent transcriptional regulation of the cardiac scn5a sodium channel by angiotensin II. Am J Physiol Cell Physiol 2008;294:C372-9.

[33] Das B, Sarkar C. Cardiomyocyte mitochondrial KATP channels participate in the antiarrhythmic and antiinfarct effects of KATP activators during ischemia and 
reperfusion in an intact anesthetized rabbit model. Pol J Pharmacol 2003;55: 771-86.

[34] Priori SG. Inherited arrhythmogenic diseases: the complexity beyond monogenic disorders. Circ Res 2004;94:140-5.

[35] Angevine CM, Herold KAG, Vincent OD, Fillingame RH. Aqueous access pathways in ATP synthase subunit a. Reactivity of cysteine substituted into transmembrane helices 1, 3, and 5. J Biol Chem 2007;282:9001-7.

[36] Alrasadi K, Ruel IL, Marcil M, Genest J. Functional mutations of the ABCA1 gene in subjects of French-Canadian descent with HDL deficiency. Atherosclerosis 2006;188:281-91.

[37] Reddy MVPL, Iatan I, Weissglas-Volkov D, Nikkola E, Haas BE, Juvonen M, et al. Exome sequencing identifies 2 rare variants for low high-density lipoprotein cholesterol in an extended family. Circ Cardiovasc Genet 2012;5:538-46.

[38] Khatami M, Heidari MM. Pathogenicity analysis of G9055A mutation in mitochondrial ATPase 6 gene in Iranian patients with familial Brugada Syndrome The 3rd Iranian Conference on Bioinformatics; 2010.

[39] Priori SG, Napolitano C, Giordano U, Collisani G, Memmi M. Brugada syndrome and sudden cardiac death in children. Lancet 2000;355:808-9.

[40] Skinner JR, Chung SK, Montgomery D, McCulley CH, Crawford J, French J, et al. Nearmiss SIDS due to Brugada syndrome. Arch Dis Child 2005:90:528-9.

[41] Opdal SH, Rognum TO. The sudden infant death syndrome gene: does it exist? Pediatrics 2004;114:e506-12.
[42] Opdal SH, Rognum TO, Torgersen H, Vege A. Mitochondrial DNA point mutations detected in four cases of sudden infant death syndrome. Acta Paediatr 1999;88: 957-60.

[43] Minocherhomji S, Tollefsbol TO, Singh KK. Mitochondrial regulation of epigenetics and its role in human diseases. Epigenetics 2012;7:326-34.

[44] Liou C-W, Chen J-B, Tiao M-M, Weng S-W, Huang T-L, Chuang J-H, et al. Mitochondrial DNA coding and control region variants as genetic risk factors for type 2 diabetes. Diabetes 2012;61:2642-51.

[45] Kofler B, Mueller EE, Eder W, Stanger O, Maier R, Weger M, et al. Mitochondrial DNA haplogroup $\mathrm{T}$ is associated with coronary artery disease and diabetic retinopathy: a case control study. BMC Med Genet 2009;10:35.

[46] Sawabe M, Tanaka M, Chida K, Arai T, Nishigaki Y, Fuku N, et al. Mitochondria haplogroups A and M7a confer a genetic risk for coronary atherosclerosis in the Japanese elderly: an autopsy study of 1,536 patients. J Atheroscler Thromb 2011; 18:166-75.

[47] Lizotte E, Junttila MJ, Dube MP, Hong K, Benito B, DEZ M, et al. Genetic modulation of Brugada syndrome by a common polymorphism. J Cardiovasc Electrophysiol 2009; 20:1137-41.

[48] Sommariva E, Pappone C, Martinelli Boneschi F, Di Resta C, Rosaria Carbone M, Salvi E et al. Genetics can contribute to the prognosis of Brugada syndrome: a pilot model for risk stratification. Eur J Hum Genet 2013;21:911-7. 